\title{
Hereditary and environmental factors causing total joint replacement due to hip and knee osteoarthritis - a twin registry based prospective cohort study
}

\author{
Karin Magnusson and Kåre Birger Hagen \\ National Advisory Unit on Rehabilitation in Rheumatology, Diakonhjemmet Hospital \\ karin.magnusson@diakonsyk.no
}

\begin{abstract}
The relative contribution of genetic factors and more modifiable environmental factors to a clinically relevant osteoarthritis (OA) diagnosis is unkown. In this paper we present an ongoing study on the genetic contribution to total joint replacement (TJR) due to hip and knee OA and effects of lifestyle and lifestyle related conditions on TJR due to OA. Using the National ID number, we have linked data on incident OA from the Norwegian Arthroplasty Registry with the Norwegian Twin Registry in 2014, thus obtaining a population based cohort of same-sex twins born 1915-60. Data on height, weight and lifestyle were selfreported in questionnaires conducted between 1978 and 1992. The monozygotic (MZ) and dizygotic (DZ) concordances as well as the genetic contribution vs. contribution of more modifiable, environmental factors to arthroplasty will be examined in separate analyses for the hip and the knee joint. The sample comprised $\mathrm{N}=18058$ twins $(\mathrm{N}=3803 \mathrm{MZ}$ and $\mathrm{N}=5226 \mathrm{DZ}$ pairs) including $\mathrm{N}=9650$ (53.4\%) females and a mean (SD) age of 38 (12.3) years at questionnaire response. Some preliminary analyses have been performed showing a higher concordance for TJR due to hip OA among MZ (0.36) than DZ twins (0.16), which may be consistent with a genetic contribution to hip OA. Results for the knee joint as well as final results from hereditary analyses and co-twin control analyses will be published consecutively from 2016.
\end{abstract}

This is an open access article distributed under the Creative Commons Attribution Licence, which permits unrestricted use, distribution, and reproduction in any medium, provided the original work is properly cited.

\section{INTRODUCTION}

Osteoarthritis (OA) is a frequently occurring joint disease responsible for pain and disability at the individual level and high costs at the societal level $(1,2)$. The most frequently affected joints are the hands, hips and knee joints. Previous studies of OA have mainly considered mild radiographic joint changes not taking severe joint pain and functional disability into account (3). Total joint replacement (TJR) surgery is indicated when both radiographic changes, severe joint pain and disability are present and other treatment modalities have failed (4). TJR is major intervention for the individual and associated with high societal costs that should be avoided whenever possible.

No disease-modifying drug exist for $\mathrm{OA}$ and a thorough understanding of its risk factors is crucial in order to prevent the disease. Potential modifiable risk factors for severe OA include obesity, physical activity levels and poor cardiometabolic health (5-8). However, severe OA may potentially also be explained by non-modifiable hereditary factors as well as age and sex. In a smaller and selected British twin cohort, the genetic contribution to mild/unsymptomatic (radiographically defined) hip and knee OA was estimated to $39-65 \%(9-11)$. The genetic contribution to severe OA including total joint replacement has to our knowledge only been explored in one previous study. Recent Danish studies found a heritability of $47 \%$ for TJR due to hip OA and only $18 \%$ for TJR due to knee OA $(12,13)$.
Twin studies of rheumatic diseases with more distinct diagnostic criteria such as rheumatoid arhtritis found a heritability of $60 \%$ (14).

The poor knowledge of the relative contribution of hereditary and environmental factors causing severe OA makes the interpretation of previous OA risk factor studies challenging. The Nord-Trøndelag Health Study (HUNT) found a higher body weight especially at young age to be associated with future total joint replacement in the Norwegian Arthroplasty Registry (15-17), which is confirmed in studies using milder OA definitions $(7,18)$. Total joint replacements due to OA may further be a result of a low physical activity level although it is unclear whether a low activity level is harmful or beneficial $(8,19,20)$. Explanatory mechanisms for the observed associations may, except for altered mechanical joint loading, be the altered systemic circulatory factors due to excess fat tissue and/or poor physical fitness (21-23). However, previous studies of OA causes and causal pathways may be confounded due to the lack of adjustment for hereditary factors and very few studies have attempted at quantifying the degree of confounding.

A linkage of the Norwegian Twin Registry and the Norwegian Arthroplasty Registry will allow for a less biased study of causes for total joint replacements due to $\mathrm{OA}$ in a general population and give insight into the genetic contribution to severe OA. Hence, using a population based twin registry design, our main aim is to investigate the hereditary contribution to total joint 
Table 1. Descriptive characteristics of the Norwegian Twin Registry and the Norwegian Arthroplasty Registry.

\begin{tabular}{lccc}
\hline & $\begin{array}{c}\text { Total sample } \\
\mathrm{N}=18058\end{array}$ & $\begin{array}{c}\text { TJR due to hip OA } \\
\mathrm{N}=594\end{array}$ & $\begin{array}{c}\text { No TJR due to hip OA } \\
\text { N=17464 }\end{array}$ \\
\hline Birth year, mean (SD) & $1942(12.7)$ & $1935(10.8)$ & $1942(12.7)$ \\
Sex, f, N(\%) & $9650(53.4)$ & $416(70.0)$ & $9234(52.9)$ \\
Prosthesis operation due to other causes & & & \\
than OA, N (\%) & $202(0.0)$ & NA & $202(0.0)$ \\
Time to TJR, years, mean (SD) & $27.9(1.6)$ & $17.6(7.2)$ & $15.8(7.9)$ \\
Age at prosthesis operation, mean (SD) & $69(8.4)$ & $69(8.4)$ & $65(11.4)$ \\
Dead by 2014, N(\%) & $5159(28.6)$ & $169(28.5)$ & $4990(28.6)$ \\
\hline
\end{tabular}

replacement due to hip and knee OA and to investigate the effect of lifestyle and lifestyle related conditions on total joint replacement due to hip and knee OA.

\section{Methods}

The study is a prospective cohort study based on a linkage of the Norwegian Twin Registry and the Norwegian Arthroplasty Registry on the National ID number. The Norwegian Twin Registry was established in 2009 at the Norwegian Institute of Public Health merging three major population-based Norwegian Twin Panels: Panel I (twins born 1895-1945), Panel II (twins born 1915-1960) and Panel III (twins born 1967-1979) (21). Panel II, which has some overlap with panel I is the most suitable for linkage with other registries since data on zygosity is available. In 197882 and in 1988-1992, postal questionnaires regarding basic demographics, general health, current weight and height as well as lifestyle, comorbidities, physical and mental health were sent to each twin in Panel II who responded to a previous general zygosity questionnaire. Hence, we included complete same-sex monozygotic (MZ) and dizygotic (DZ) twin pairs from Panel II. No twin pairs with opposite sex were registered in this sample. We excluded twins who had no co-twin registered due to early death or not being willing to participate.

The Norwegian Arthroplasty Registry was established in 1987 as a national hip joint replacement registry and was extended to include all arthroplasty of artificial joints in 1994 (22). Its main purpose is to detect inferior results of implants as early as possible. All orthopedic surgeons at all the Norwegian hospitals participate and are instructed to report all primary operations and all revisions. After each primary joint replacement, the surgeon fills in a one-page form regarding operation technique and description about implant parts. The form takes only about a minute to complete ensuring a complete registry. In total, $>95 \%$ of all prosthesis operations due to OA are reported and approximately 10.000 surgeries of hip and knee OA are registered yearly (23).

Prevalent and incident hip and knee arthroplasty due to primary OA in the left or right leg were our main outcome variables (separate analyses for the hip and the knee joint). Arthroplasty due to other causes than
OA such as fractures or inflammatory rheumatic diseases were not considered in this study. We will estimate the heritability for TJR due to hip and knee OA using the classical twin model. A co-twin control design will be used for the analyses of the potentially modifiable exposures obesity, low activity levels, diabetes, hypertension and angina pectoris. Exposure data are currently being quality assured and will be examined as potential causes for TJR due to OA in 2017 and onwards.

\section{Preliminary Results}

The sample comprised 18058 twins of which 3803 were monozygotic (MZ) twin pairs and 5226 dizygotic (DZ) same sex twin pairs. Some descriptive characteristics of the total sample and of persons having TJR due to hip OA are available and are presented in Table 1. Casewise and pairwise concordance rates as well as tetrachoric correlations for the presence of TJR due to hip OA are presented in Tables 2 and 3. We will find frailty correlations from multilevel survival models and estimate the amount of the variance in TJR due to hip OA that is due to hereditary, common and unique environmental factors. Similar statistics will be worked out for TJR due to knee OA.

Table 2. MZ twins.

\begin{tabular}{lccr}
\hline & $\begin{array}{c}\text { TJR due to } \\
\text { hip OA, } \\
\text { twin 2 }\end{array}$ & $\begin{array}{c}\text { No TJR due } \\
\text { to hip OA, } \\
\text { twin 2 }\end{array}$ & Total \\
\hline TJR due to hip OA, twin 1 & 64 & 116 & 180 \\
No TJR due to hip OA, twin 1 & 105 & 3518 & 3623 \\
Total & 169 & 3634 & 3803 \\
\hline
\end{tabular}

Casewise concordance $=(64+64) /(169+180)=0.36$

Pairwise concordance $=64 / 285=0.22$

Tetrachoric correlation $=0.71$

Table 3. DZ twins.

\begin{tabular}{lccr}
\hline & $\begin{array}{c}\text { TJR due to } \\
\text { hip OA, } \\
\text { twin 2 }\end{array}$ & $\begin{array}{c}\text { No TJR due } \\
\text { to hip OA, } \\
\text { twin 2 }\end{array}$ & Total \\
\hline TJR due to hip OA, twin 1 & 37 & 179 & 216 \\
No TJR due to hip OA, twin 1 & 205 & 4805 & 5010 \\
Total & 242 & 4984 & 5226 \\
\hline
\end{tabular}

Casewise concordance $=(37+37) /(242+216)=0.16$

Pairwise concordance $=37 / 421=0.09$

Tetrachoric correlation $=0.41$ 


\section{CONCLUSION}

Preliminary results show higher concordance rates in $\mathrm{MZ}$ twins than in DZ twins indicating a significant genetic component for having a TJR due to hip OA.
Twin models using liability and frailty approaches are currently being compared. Final results from hereditary analyses and co-twin control analyses will be published consecutively from 2016.

\section{REFERENCES}

1. Lawrence RC, Felson DT, Helmick CG, Arnold LM, Choi H, Deyo RA, et al. Estimates of the prevalence of arthritis and other rheumatic conditions in the United States. Part II. Arthritis Rheum 2008;58(1):26-35.

2. Slatkowsky-Christensen B, Mowinckel P, Loge JH, Kvien TK. Health-related quality of life in women with symptomatic hand osteoarthritis: a comparison with rheumatoid arthritis patients, healthy controls, and normative data. Arthritis Rheum 2007;57(8):1404-9.

3. Clauw DJ, Witter J. Pain and rheumatology: thinking outside the joint. Arthritis Rheum 2009;60(2):321-4.

4. Lohmander LS, Roos EM. Clinical update: treating osteoarthritis. Lancet 2007;370(9605):2082-4.

5. Hoeven TA, Kavousi M, Clockaerts S, Kerkhof HJ, van Meurs JB, Franco O, et al. Association of atherosclerosis with presence and progression of osteoarthritis: the Rotterdam Study. Ann Rheum Dis 2013;72(5): 646-51.

6. Sowers M, Karvonen-Gutierrez CA, Palmieri-Smith R, Jacobson JA, Jiang Y, Ashton-Miller JA. Knee osteoarthritis in obese women with cardiometabolic clustering. Arthritis Rheum 2009;61(10):1328-36.

7. Jiang L, Rong J, Wang Y, Hu F, Bao C, Li X, et al. The relationship between body mass index and hip osteoarthritis: a systematic review and meta-analysis. Joint Bone Spine 2011;78(2):150-5.

8. Michaelsson K, Byberg L, Ahlbom A, Melhus H, Farahmand BY. Risk of severe knee and hip osteoarthritis in relation to level of physical exercise: a prospective cohort study of long-distance skiers in Sweden. PLoS One 2011;6(3):e18339.

9. MacGregor AJ, Antoniades L, Matson M, Andrew T, Spector TD. The genetic contribution to radiographic hip osteoarthritis in women: results of a classic twin study. Arthritis Rheum 2000;43(11):2410-6.

10. Spector TD, Cicuttini F, Baker J, Loughlin J, Hart D. Genetic influences on osteoarthritis in women: a twin study. BMJ 1996;312(7036):940-3.

11. MacGregor AJ, Li Q, Spector TD, Williams FM. The genetic influence on radiographic osteoarthritis is site specific at the hand, hip and knee. Rheumatology (Oxford) 2009;48(3):277-80.

12. Skousgaard SG, Skytthe A, Moller S, Overgaard S, Brandt LP. Sex differences in risk and heritability estimates on primary knee osteoarthritis leading to total knee arthroplasty: a nationwide population based follow up study in Danish twins. Arthritis Res Ther 2016;18(1):46.

13. Skousgaard SG, Hjelmborg J, Skytthe A, Brandt LP, Moller S, Overgaard S. Probability and heritability estimates on primary osteoarthritis of the hip leading to total hip arthroplasty: a nationwide population based follow-up study in Danish twins. Arthritis Res Ther 2015;17:336.

14. MacGregor AJ, Snieder H, Rigby AS, Koskenvuo M, Kaprio J, Aho K, Silman AJ. Characterizing the quantitative genetic contribution to rheumatoid arthritis using data from twins. Arthritis Rheum 2000;43(1):30-7.

15. Flugsrud GB, Nordsletten L, Espehaug B, Havelin LI, Engeland A, Meyer HE. The impact of body mass index on later total hip arthroplasty for primary osteoarthritis: a cohort study in 1.2 million persons. Arthritis Rheum 2006;54(3):802-7.

16. Apold H, Meyer HE, Nordsletten L, Furnes O, Baste V, Flugsrud GB. Risk factors for knee replacement due to primary osteoarthritis, a population based, prospective cohort study of 315,495 individuals. BMC Musculoskelet Disord 2014;15:217.

17. Apold H, Meyer HE, Nordsletten L, Furnes O, Baste V, Flugsrud GB. Weight gain and the risk of knee replacement due to primary osteoarthritis: a population based, prospective cohort study of 225,908 individuals. Osteoarthritis Cartilage 2014;22(5):652-8.

18. Jiang L, Tian W, Wang Y, Rong J, Bao C, Liu Y, et al. Body mass index and susceptibility to knee osteoarthritis: a systematic review and meta-analysis. Joint Bone Spine 2012;79(3):291-7.

19. Bakke Johnsen M, Hellevik A, Baste V, Furnes O, Langhammer A, Flugsrud G, et al. Physical activity and the risk of hip or knee replacement due to primary osteoarthritis. A population based cohort study of 66.863 persons from the HUNT study. Osteoarthritis and Cartilage 2015;23 (Supplement 2):A175-A176.

20. Williams PT. Effects of running and walking on osteoarthritis and hip replacement risk. Med Sci Sports Exerc 2013;45(7):1292-7.

21. Magnusson K, Østerås N, Haugen I, Mowinckel P, Nordsletten L, Natvig B, et al. No strong relationship between body mass index and clinical hand osteoarthritis - results from a population-based case-control study. Scand J Rheumatol 2014;1-7. 
22. Magnusson K, Hagen KB, Østerås N, Nordsletten L, Natvig B, Haugen IK. Diabetes is associated with increased hand pain in erosive hand osteoarthritis - data from a population-based study. Arthritis Care Res (Hoboken) 2015;67(2):187-95.

23. Yusuf E. Metabolic factors in osteoarthritis: obese people do not walk on their hands. Arthritis Res Ther 2012;14(4):123..

24. Nilsen TS, Brandt I, Magnus P, Harris JR. The Norwegian Twin Registry. Twin Res Hum Genet 2012;15(6): 775-80.

25. Havelin LI, Engesæter LB, Espehaug B, Furnes O, Lie SA, Vollset SE. The Norwegian Arthroplasty Register: 11 years and 73,000 arthroplasties. Acta Orthop Scand 2000;71(4):337-53.

26. Helse Bergen HF OkHu. Rapport juni 2014. 2015. Nasjonalt register for leddproteser. 